\title{
Tingkat Persepsi Nilai, Risiko Dan Preferensi Masyarakat Banjarmasin Terhadap Produk Hijau Berdasarkan Demografis
}

\section{Rizka Zulfikar, S.Tp, MM"1 Prihatini Ade Mayvita, SE, MMl}

${ }^{11}$ rizkazulfikar@gmail.com, ${ }^{21}$ ademayvita@gmail.com

\section{Abstrak}

Peneitian ini bertujuan untuk mengkaji tingkat persepsi nilai, risiko daan preferensi masyarakat Banjarmasin berdasarkan demografis dan selanjutnya digunakan untuk mendapatkan segmen potensial untuk pemasaran produk hijau. Populasi dan Sampel adalah masjarakat kata Banjarmasin sebarnak 150 responden secara non purposive sampling. Teknik analisis data yang dizunakan : analisis deskriptif kualitatifkuantitatif, analisa perbandingan rata-rata dan permodelan dengan SEM. Masil penelitian menemukan bahwa Tingkat persepsi nilai dan persepsi risiko masyarakat kota Banjarmasin terhadap produk hijau sudah cukup baik sedangkan tingkat preferensi masyarakat masih maporitas dalam kategori rendah, sedangkan Segmen demografis potensial yang dapot digdikan sebagai target pasar produk hijau artara lain adalah gender perempuan, usia 31 - 40 tahun dan di atas 50 tahun, pekerjaan swasta dian pelajar/mahasiswa, penghasilan antara Rp 2 Juta R99 4,9 Juta dan tinglat pendidikan Diploma dan S-1. Variabel yang dipenearuhi oleh demografis adalah persepsi nilai dan preferensi masyarakat terhadap preduk hijau.

\section{Latar Belakang}

Dalam pemasaran produk hilau, kegistan memahami karaiteristik konsumen menjad hal yang sangat penting agar para pengembang produk dapat menertukan strateg pemasaran perusahan, Salzh sat. tratez pemasaran perusahaan. salat satu kegiatan vang seringkail dilakikan untuk memahami kansumen adalah segmenta di segmentasi pasar yang seringkal digunakan adalah segmentasi demografis karena variabel cenderung lebih mudah divikur dan memiliki penzaruh terhadap keputusan pembelian konsumen .

\section{Tujuan}

$$
\begin{aligned}
& \text { a. Mendapatkan gambaran tentang } \\
& \text { tingkat persepsi nilai, persepsi risiko } \\
& \text { dan preferensi masyarakat Barijarmasin } \\
& \text { terhadep produk hijau } \\
& \text { b. Menentukan segmentasi potensial yang } \\
& \text { dapat dijadikan target pemasaran } \\
& \text { produk hijau. } \\
& \text { c. Serperan serta dalam kegiatan yang } \\
& \text { mendukung pengembangan produk } \\
& \text { hijau. }
\end{aligned}
$$

\section{Metode}

- Penelitian dilaksanakan di Banjarmasin pada bulan lanuari - Mei 2018

- Populasi adalah masyarakat kota Banjarmasin dengan jumlah sampel = 150 sampel.

- jumlah minimum sampel didapat denean rumus slovin.

- Instrumen penelitian adalah Kuesioner

- Teknik analisis data : (1) analisis deskriptif kualitatif - kuantitatif, (3) onalisa compare means, dan (3) analsis Stuctural Equation Model
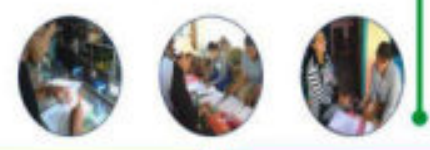

inesearch

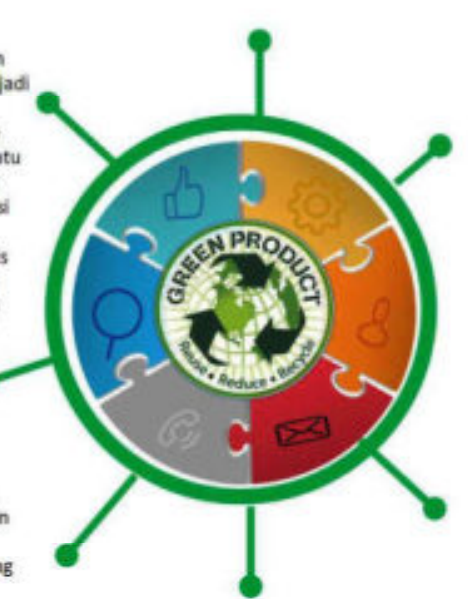

\section{Hasll}

Rata-Rata Perseps Nilai, Pisìn da

Preferensi Tetheps Nilai, Risì̀o Foluter De-
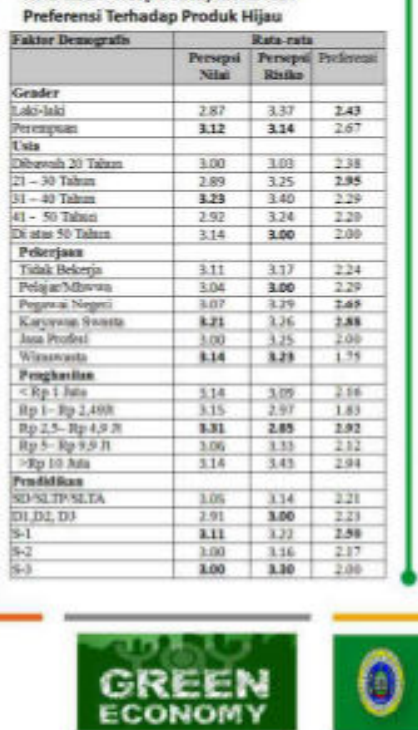

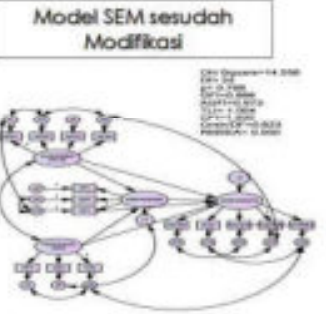

Hasil Uji Pengaruh

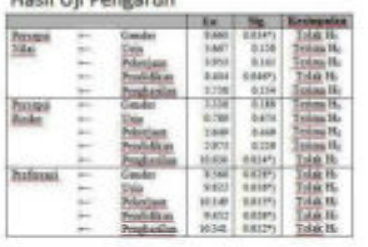

Faktor demografis harya memberikan pengaruh yang nvata terhadap tingkat persepsi nilai dan preferensi masparaka pen tidak berpenganth nyata tingkat persepsi risko.

\section{Simpulan \& Saran}

Masyarakat Banjarmasin sudah memiliki tingkat penilaian yang cukup baik terhadap persepsi nilai dan risiko namun masih rendah dalam hal tingkat preferensi. Segmentasi potensial yang didapatkan dalam penelitian ini adalah : perempuan, usia 31 - 40 tahun dan di atas 50 tahun, pekerjaan swasta dan pelajar/mahasiswa, penghasilen antara Ro 2 luts - Rp $4.9 \mathrm{Jut}$ dan tinglat pendidikan Diptome dan 5 .

\section{Ucapan Terima Kasih}

Kami haturkan veagan terima kasih kepada Yoyasan Uniska Banjarmasin yane telah membantu pendansan peneiltian ins: 


\section{Daftar Pustaka :}

Zulfikar, R., \& Mayvita, P. A. (2017, December). Tingkat Kepercayaan dan Minat Beli Masyarakat Banjarmasin Terhadap Produk Hijau Berdasarkan Segmentasi Demografis. In Proceeding of National Conference on Asbis (Vol. 2, No. 1, pp. 410-426).

Zulfikar, R., \& Mayvita, P. A. (2018). The Relationship of Perceived Value, Perceived Risk, and Level of Trust Towards Green Products of Fast Moving Consumer Goods Purchase Intention. JEMA: Jurnal Ilmiah Bidang Akuntansi dan Manajemen, 15(2), 1-14.

Zulfikar, R., \& Banjarmasin, U. I. K. M. The Structural Equation Models of Environmental Concern and Knowledge To Green Trust and Green Purchase Intention Towards Green Products (Guideliness).

Zulfikar, R., \& Mayvita, P. A. (2019). Does Green Economy Video Really Work? The Effectiveness of Using Video Content Marketing in Forming MSMEs Perception and Behavior to Implement Green Economy. JEMA: Jurnal Ilmiah Bidang Akuntansi dan Manajemen, 16(1), 34-45.ar

Zulfikar, R., \& Mayvita, P. A. (2019). DIVERSIFIKASI PRODUK OLAHAN BERBASIS IKAN PATIN SEBAGAI POTENSI USAHA BAGI PANTI ASUHAN AL AMIN DAN SULTAN SURIANSYAH BANJARMASIN. JURNAL PENGABDIAN AL-IKHLAS UNIVERSITAS ISLAM KALIMANTAN MUHAMMAD ARSYAD AL BANJARY, 4(1). 